\title{
An Evaluation of Order-picking Tour Efficiency in Two-block Warehouses
}

\author{
Ömer Öztürkoğlu \\ Department of Business Administration, \\ Yaşar University, Bornova, Izmir 35100, Turkey \\ Email: omer.ozturkoglu@yasar.edu.tr (Corresponding Author) \\ Deniz Hoşer \\ Cutting Department, \\ Hugo Boss, Gaziemir, Izmir 35410, Turkey \\ Email: deniz.hoser@gmail.com
}

\begin{abstract}
This study investigates the effects of critical operational and strategical decisions in order-picking warehouses on order pickers' tour lengths. For this study, one of the most-commonly applied layouts in practice, called two-block layout with a central cross aisle, was considered. A full factorial experimental design and multiple-comparisons (Bonferroni t-tests) were applied to statistically determine the significance of various levels of storage policies, pick-list sizes, warehouse shape ratios, warehouse sizes and their all interactions on average tour length. The analysis showed that deeper storage areas were superior to wider areas in small- and medium-sized warehouses. Warehouse designs with a 1:1 width-to-depth shape ratio offered the most robust layouts. Within-storage aisle policy significantly reduced order-picking tour length and generally outperformed other storage policies.
\end{abstract}

Keywords: order-picking, warehouse, distribution center, storage policy, routing

\section{INTRODUCTION}

Warehouses or distribution centers are places to keep products safe and ready until a customer order is received. Because of their importance to serving customers on time, they play a critical role in the success of companies' logistics systems. The growth in online retailing has increased the importance of efficient management of warehouse operations, such as receiving, put-away, order-picking and shipping. Because of increasing demand for quick shipments in online businesses, the need for short response times to customer orders has become inevitable. According to warehouse managers in this industry, "internal order cycle time" is one of the most critical performance measures (Manrodt, 2018). Thus, order-picking operations have the most significant effects on customer response times and customer satisfaction. Order-picking is also the costliest warehouse operation, mainly due to travel time between locations (Tompkins et al., 2010). While travel time is inevitable for an order picker to fulfill an order, it is an unproductive and non-value-adding activity during this operation (Bartholdi and Hackman, 2011).
Particularly in warehouses that handle many small units, workers visit many locations per trip to fulfill customer orders in a system called picker-to-part order-picking systems. In this system, order pickers travel along the aisles in whatever sequence enables them to collect the required products in an appropriate order from their storage locations to make the order ready for shipping. The order picker then returns to the pick-up and deposit (P\&D) point to leave the picked items before picking the next batch. The pick-list given to an order picker contains the order lines that should be processed in each tour. An order line includes information about the requested item, its quantity and storage location. The total distance an order picker travels to process the picklist, starting and ending at the $P \& D$ point, is called the orderpicking tour length. Because order-picking time is proportional to tour length, the items requested in the picklist should be retrieved in an order that minimizes total tour length. This increases throughput and productivity, thereby helping to reduce response times to customer orders and operational costs.

Although high throughput can be achieved with appropriate, highly-automated material handling systems, such as automated storage and retrieval systems, the majority of warehouses have avoided high levels of automation for decades because of high investment costs and inflexibility. However, whereas automation was previously associated with low flexibility due to fixed automation systems or robots with limited capabilities and functionality, the flexibility of automation has recently increased with the emergence of autonomous or collaborative robots powered by navigational tools and with grasping capabilities to assist with loading, unloading, picking, transportation, storage and sorting (Futch, 2017). This is evidenced by the e-commerce industry leader, Amazon, which bought and installed 45,000 Kiva robots across its 20 fulfillment centers - a 50 percent increase on the previous year (Shead, 2017). Nevertheless, whether the order picker is a worker or an autonomous robot, or work with collaborative robots travel time during orderpicking operations ultimately remains the major determinant of its operational efficiency.

While order-picking tour length can be reduced by appropriate operational strategies, warehouse layout is a 
fundamental determinant of travel time. First, layout parameters, such as aisle number and width, and storage area width and depth, significantly affect travel routes and their lengths. Second, warehouse layouts are hard to change once they have been built. Warehouse managers therefore mostly focus on operational activities, such as routing order pickers, batching different customer orders to increase pick density, assigning workers to zones and allocating goods to locations with respect to their demand pattern, turnover rate or particular characteristics within a fixed layout. Thus, this study aims to provide both strategic and managerial insights for warehouse managers in deciding the best configurations of both layout and operations to increase the efficiency of warehouse order-picking operations. To do so, it investigates the effects of various layout options on order-picking tour length, such as warehouse size and shape ratio, and various operational activities, such as storage policies and pick-list sizes. The analyses were performed on one of the most widely implemented types of warehouse layout in both industry and academic research.

The organization of this paper is as follows. The next section discusses the most relevant previous studies to the research problem before the research methodology and the conducted experimental design are explained. Then it presents the results of the experiments and compares them with the findings of previous studies. It ends with some concluding remarks and highlights managerial insights.

\section{PREVIOUS STUDIES}

Researchers have extensively studied on order-picking operations in recent decades. Most previous studies have

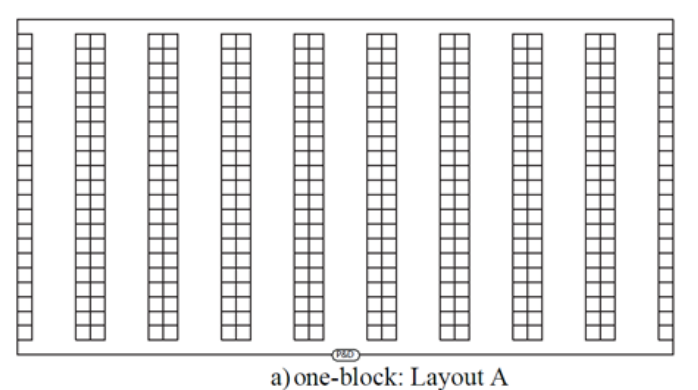

Figure 1 Representations of one-block (a) and two-block (b) warehouse layouts

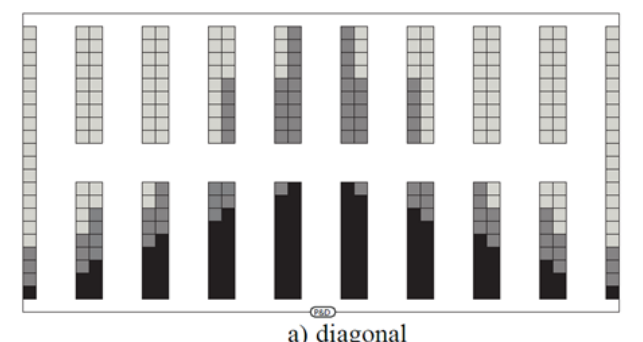

a) diagonal

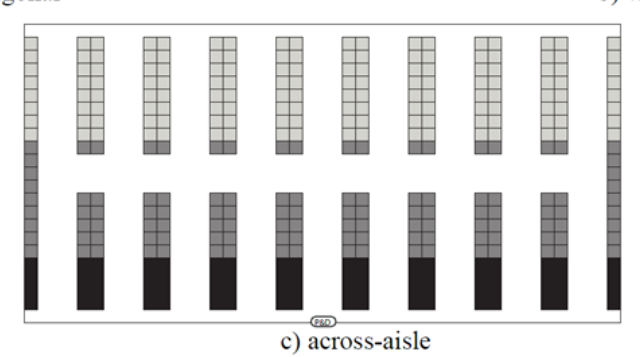

Figure 2 Implementations of class-based storage policies for centrally-located single P\&D point: (a) diagonal (turnover); (b) within aisle; (c) across-aisle

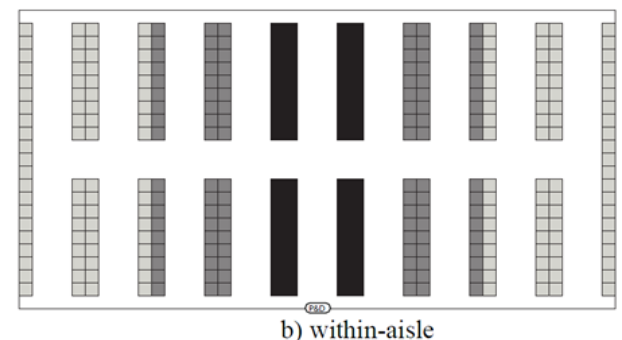

mainly focused on calculating the optimal routes for order pickers or the allocation of products to storage locations based on a fixed policy for a given layout. Additionally, some studies have focused on batching different customers' orders or dividing a warehouse into zones. Because this study assumes that orders are already batched before generating routes and that zones can be considered as small isolated storage areas, these issues are not considered here.

\subsection{Warehouse Layout}

The basic warehouse layout, known as the one-block warehouse and called Layout A hereafter, has front and rear cross aisles to travel between picking aisles (see Figure 1a). While one-block warehouses are mainly preferred in unitload storage areas in which the single-command operation is preferred, two-block warehouses are better choice for orderpicking warehouses. As shown in Figure 1b, two-block warehouses, called Layout B hereafter, have an extra cross aisle at the center of the warehouse to facilitate travel between storage locations that are arranged along numerous picking aisles. Although having an extra cross aisle can reduce order-picking route length, increasing the number of additional cross aisles may also increase travel distance because the extra aisle spaces increase the overall storage area. Thus, Vaughan and Petersen (1999), Berglund and Batta (2012), and Hsieh and Tsai (2006) have demonstrated that order-picking tour length increases if there are more than two central cross aisles whereas two central cross aisles yield slightly shorter tour lengths than a single central cross aisle. Accordingly, the majority of warehouses in the industry utilize only one central cross aisle.

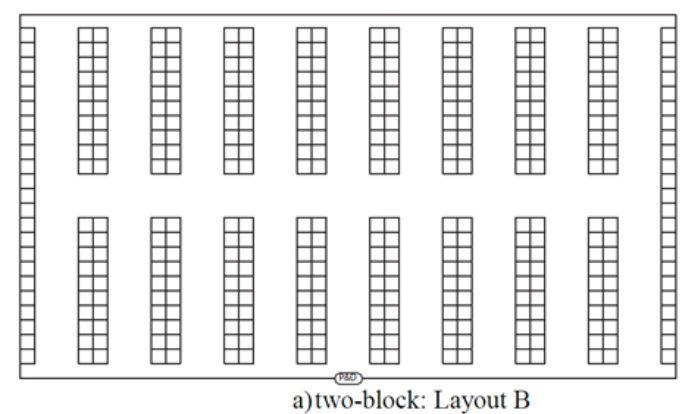

within-aisle 

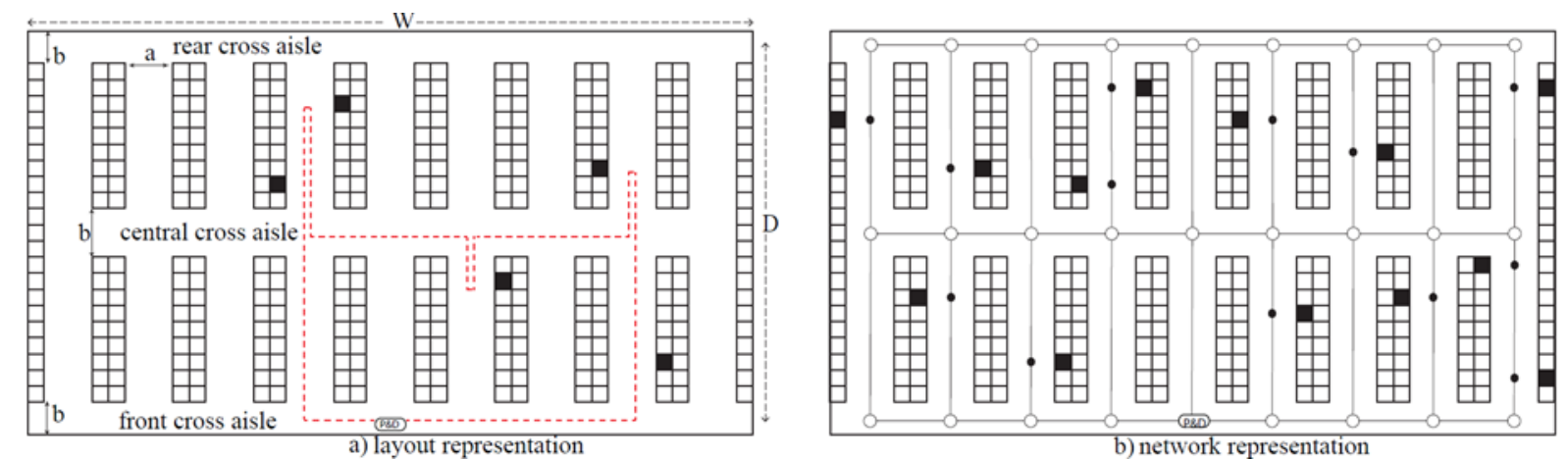

Figure 3 Warehouse layout parameters and a sample order-picking tour

\subsection{Storage Policies}

Four general storage polices are applied in warehouses to manage storage locations: randomized, dedicated, turnover-based and class-based. In randomized storage, a location is assigned to a stock keeping unit (SKU) without considering its turnover. That is, each storage location is assumed to be used equally likely by any SKU, resulting in uniform picking from locations. Because computerized management is required to determine the locations to be visited based on customer requests, efficient application of a randomized storage policy depends on the quality of the information system, such as a warehouse management system (WMS). In practice, however, workers tend to put SKUs in the closest open locations to the P\&D point. Park and Lee (2007) showed that randomized storage (or uniform picking) can be used to approximate the closest-to-open location strategy.

Because of the managerial difficulties of managing a randomized storage policy, managers reserve some locations for certain products in a dedicated storage policy. Because workers become familiar with product locations over time, this policy reduces search and travel time during each picking operation compared to randomized storage. However, as Bartholdi and Hackman (2008) showed, dedicated storage also reduces storage utilization by about 50 percent compared to randomized storage. Turnover-based storage improves the positive effect of dedicated storage on picking time by reserving the most convenient locations closest to P\&D points for the most active SKUs. Because the activity levels of SKUs can change over time, warehouse managers tend to reserve a specific set of locations for each set of SKUs. Thus, in class-based storage, while locations are divided into classes according to their closeness to the P\&D point, SKUs are partitioned into classes based on their turnover. An SKU in a class is then stored randomly within its respective class of locations. Class-based storage is thus a hybrid policy incorporating dedicated and randomized policies that aims to both improve storage utilization and shorten picking time. In practice, there are three main implementations of class-based storage: diagonal, acrossaisle and within-aisle (see Figure 2 for schematic representations).

\subsection{Order-picking Routing}

Routing is one of the extensively studied topics in order-picking literature. Even though previous studies have produced both optimal and non-optimal but efficient routing algorithms, they are hardly ever applied in warehouses because the optimal routes are complex and difficult for human workers to follow. Therefore, both practitioners and researchers have focused on intuitively-generated heuristics, such as s-shape or traversal, largest-gap, mid-point, return and aisle-by-aisle (for details, see Hall, 1993; Petersen, 1997; Petersen, 1999; and Roodbergen and De Koster, 2001). However, emerging wearable technologies, such as Google glasses with augmented reality technologies, and autonomous vehicles with navigation systems have increased the usability of optimal tours so optimal routing algorithms may well be implemented in the warehousing industry in the near future. Several optimal algorithms have been developed to solve optimal tours in a warehouse based on the well-known traveling salesman problem (TSP). Ratliff and Rosenthall's pioneering study (1983) showed that an optimal order-picking tour can be solved in polynomial time for one-block warehouses (Layout A). Roodbergen and De Koster (2001) then extended this algorithm for two-block warehouses (Layout B), and developed an exact algorithm to solve the order-picking tour in polynomial time. Recently, Scholz et al. (2016) proposed a mathematical model to solve the optimal order-picking tour for any number of central cross aisles.

Jarvis and McDowell (1991), Petersen (1997), Petersen (1999), Petersen and Schmenner (1999), Petersen (2000), Petersen (2002), Petersen and Aase (2004), Ho et al. (2008) and Thomas and Meller (2014) have deeply analyzed Layout A regarding the effects of varying zone and batching policies, routing algorithms, pick-list sizes, shape ratios, number and locations of $P \& D$ points, warehouse sizes, storage policies and demand distributions. Their findings offer valuable insights to warehouse managers for managing their order-picking operations efficiently and optimizing their layouts even if they lack a central cross aisle. On the other hand, several studies have demonstrated that having one central cross aisle reduces order-picking tour in comparison to Layout A (Vaughan and Petersen, 1999; Berglund and Batta, 2012). Therefore, many order-picking warehouses now include at least one central cross aisle. Yet, even though Layout B is one of the most commonly seen layouts in the industry, it has still not been deeply investigated with respect to a set of design and operational factors. Only a few studies have investigated the effects of several factors on order-picking efficiency.

Le-Duc and De Koster (2005) examined a variant of the two-block warehouse and investigated the optimal shape of storage zones to minimize order-picking tour length for varying pick-list sizes, storage policies and demand skewness. Hsieh and Tsai (2006) investigated the effects of the number of cross aisles, storage policies and demand 
skewness on order-picking tour length in Layout B. Berglund and Batta (2012) also analyzed order-picking tour efficiency according to varying storage policies, levels of demand skewness while searching for best location of the central cross aisle in Layout B. They used different types of heuristic to calculate order-picking tour length. Of the previous studies, some presented conflicting results. For instance, while Berglund and Batta (2012) reported that across-aisle storage is superior to within-aisle storage for low and moderate pick-list sizes, Petersen and Schmenner (1999) found that within-aisle storage is superior to cross-aisle for any pick-list sizes. Although these contradictions may be caused by the type of layouts used (Layout A versus Layout B), other underlying reasons could be routing algorithms or the size of the experiments. For example, Roodbergen and Vis (2006) showed that the optimal layout is very sensitive to the routing policy used in tour calculations. Therefore, the main purpose of this study is to fill the research gap regarding Layout B with a comprehensive study of orderpicking tour efficiency with varying shape ratios, warehouse sizes, storage policies, demand skewness and pick-list sizes. Thus, this study aims to provide solid insights to managers regarding Layout B through comparison with previous studies' results.

\section{METHODOLOGY}

The warehouses studied here have one central cross aisle and front and rear cross aisles to ease changing aisles in warehouses where more than one location is visited. They are assumed to have single-depth racking systems. We also assume that the left and rightmost racks are attached to the walls. Picking operations are assumed to be performed from the lowest level of the racking system, called the forwardpicking area. For ease of representation, storage locations have a square-shaped footprint, with one pallet unit $(1 \mathrm{PU}=$ 10 pixels) as the adopted measure of distance. The picking aisles are assumed to be wide enough for two-way travel with picking from both sides. Therefore, the picking aisle width (a) and cross-aisle width (b) are both assumed to be three PUs. There is also only one centrally located $\mathrm{P} \& \mathrm{D}$ point at the front of the warehouse because it has been shown that it is the optimal location for minimizing tour length under randomized storage (Roodbergen and Vis, 2006). Thus, order-picking starts from the P\&D point, visits all required locations to fulfill the order and returns to the $P \& D$ point to deposit the picked items (see Figure 3a for a representative layout and a sample route). To determine the optimal route and calculate its length, we used Roodbergen and De Koster (2001)'s optimal algorithm because of its computational efficiency. The algorithm relies on a generated network of storage locations in a warehouse in which the network of a warehouse layout consists of storage locations, aisle entrance and exit points as nodes in a graph with appropriate arcs (see Figure 3b for the network representation of the warehouse). The complete order-picking tour is then characterized by partial tour sub-graphs in 25 equivalence classes. After constructing each possible equivalence class from the leftmost to the rightmost aisle, the optimal tour is determined within the set of specific equivalence classes. Roodbergen and De Koster (2001) is strongly recommended for further reading on the details of the routing algorithm.

Table 1 Experimental factors and their levels

\begin{tabular}{|l|l|l|l|}
\hline \multicolumn{1}{|c|}{ Code } & \multicolumn{1}{|c|}{ Factors } & \# Levels & \multicolumn{1}{c|}{ Levels } \\
\hline SR & Shape Ratio (width:depth) & 4 & $1: 1,2: 1,3: 1,1: 2$ \\
\hline NP & Number of Picking Aisles & 5 & $7(\mathrm{XS}), 9(\mathrm{~S}), 11(\mathrm{M}), 13(\mathrm{~L}), 15(\mathrm{XL})$ \\
\hline SP & Storage Policy & 7 & $\begin{array}{l}\text { randomized (RND), within-aisle 50/30/20 (W50), within-aisle 80/15/5 } \\
\text { (W80), diagonal 50/30/20 (D50), diagonal 80/15/5 (D80), across-aisle } \\
50 / 30 / 20(\mathrm{X} 50), \text { across-aisle 80/15/5 (X80) }\end{array}$ \\
\hline PS & & & $3,5,10,15,20,30,40,50,75,100$ items \\
\hline
\end{tabular}

Table 2 Characteristics of warehouses with different sizes and shape ratios when the 2:1 shape ratio is taken as the base

\begin{tabular}{|c|c|c|c|c|c|c|c|c|c|c|}
\hline & \multicolumn{5}{|c|}{ Shape ratio 1:1 } & \multicolumn{5}{|c|}{ Shape ratio $2: 1$} \\
\hline & XS & $\mathrm{S}$ & $M$ & $\mathbf{L}$ & $X L$ & XS & $\mathrm{S}$ & $M$ & $L$ & $\mathrm{XL}$ \\
\hline $\begin{array}{l}\text { Total \# of low-level storage } \\
\text { locations }\end{array}$ & 186 & 330 & 518 & 726 & 996 & 188 & 330 & 512 & 734 & 996 \\
\hline Width & 28 & 33 & 43 & 48 & 58 & 38 & 48 & 58 & 68 & 78 \\
\hline Height & 24 & 33 & 38 & 46 & 51 & 19 & 24 & 29 & 34 & 39 \\
\hline \multirow[t]{3}{*}{ Number of picking aisles } & 5 & 6 & 8 & 9 & 11 & 7 & 9 & 11 & 13 & 15 \\
\hline & \multicolumn{5}{|c|}{ Shape ratio 3:1 } & \multicolumn{5}{|c|}{ Shape ratio 1:2 } \\
\hline & XS & $S$ & $M$ & $L$ & $\mathrm{XL}$ & XS & $\mathrm{S}$ & $M$ & $L$ & $\mathrm{XL}$ \\
\hline $\begin{array}{l}\text { Total \# of low-level storage } \\
\text { locations }\end{array}$ & 186 & 342 & 510 & 754 & 994 & 186 & 326 & 516 & 738 & 1000 \\
\hline Width (PU) & 48 & 63 & 73 & 88 & 98 & 18 & 23 & 28 & 33 & 38 \\
\hline Height (PU) & 16 & 20 & 24 & 28 & 32 & 36 & 46 & 57 & 67 & 77 \\
\hline Number of picking aisles & 9 & 12 & 14 & 17 & 19 & 3 & 4 & 5 & 6 & 7 \\
\hline
\end{tabular}




\section{Experimental Design}

This section presents the experiment in detail to evaluate several important design and operational factors to determine which factors or combination of factors reduce order-picking tour length in Layout B. Table 1 presents details of the selected factors and their levels. The design factors are warehouse shape ratio and number of picking aisles while the operational factors are storage policies and number of picks. Additionally, storage policies are differentiated by two levels of demand skewness. Both previous studies and our observations were taken into account in determining these factors and their levels.

Shape ratio is the warehouse's width to depth ratio $(W: D)$. A warehouse that is twice as wide as its depth, i.e. $2: 1$, is assumed to be the base design in this study because this ratio is not only common in industry but also taken as optimal by several researchers, especially when there is a central P\&D point and single-command operation (Francis, 1967; Bassan et al., 1980). The other selected shape ratios are 1:2, 1:1 and 3:1, which were also considered by Petersen (1997) and Petersen and Aase (2004) in the analysis of Layout A.

Although warehouse sizes and capacities were assumed to be fixed in many previous studies, such as Petersen (1997), Petersen (1999), Petersen and Aase (2004), and Hsieh and Tsai (2006), the only detailed analysis of warehouse size and shape ratio was conducted by Thomas and Meller (2014). However, their study was also limited to Layout A with multiple P\&D points so it could not demonstrate the interaction effects of warehouse size and other factors, especially for Layout B. For clarity's sake, this study investigates the interaction effects for five warehouse sizes: extra-small (XS), small (S) medium (M), large (L) and extralarge (XL). These names are not intended to explain actual warehouse sizes in practice, these are used only for representation. These sizes are defined by the number of picking aisles arranged in the 2:1 base layout. Thus, when the shape ratio is changed, the number of picking aisles that should be arranged changes to maintain the same storage capacity as the base design. Table 2 shows the characteristics of warehouse layouts with different shape ratios and sizes. For instance, one 7-aisle warehouse has an XS storage area with seven vertical picking aisles arranged in parallel to generate a warehouse layout with an approximately 2:1 shape ratio and 188 low-level storage locations. In contrast, the equivalent layout with a 3:1 shape ratio consists of 9 vertical picking aisles and 186 storage locations.

To investigate the effects of product allocation on order-picking efficiency, this study considered randomized, diagonal, within- and across-aisle storage policies as they are common in industry (see previous section for details). In class-based storage policies, SKUs and storage locations are usually divided into three classes: A, B and C. While classA SKUs are the most frequently requested, class-B SKUs are moderately and class-C SKUs are the least frequently requested items. Although it is generally assumed that items in the same class have the same activity level, because the frequency of demand for items in each class can change over time or vary across companies, this study considers two different demand policies as follows:

- Demand policy \#1: A: 20/50; B: 30/30; C: 50/20.
- Demand policy \#2: A: 20/80, B: 30/15; C: 50/5

The first number shows the percentage of total locations reserved for SKUs in the respective class while the second represents the frequency of demand for SKUs in the class. The policies assume that SKUs in classes A, B and C occupy $20 \%, 30 \%$ and $50 \%$ of the total storage locations, irrespective of demand rates and variations in class-based storage policy. The reserved storage locations are determined based on closeness to the P\&D point and the application of the storage policy (see Figure 2 for arrangement of locations in storage policies). From the perspective of class-based storage policies, if each class has equal storage area (33.3\%) and demand rate is equal in each class $(33.3 \%)$, this policy results in randomized storage. Similar storage and demand policies were also used in several previous studies, such as Le-Duc and De Koster (2005), Berglund and Batta (2012) and Petersen et al. (2004).

Last, this study also explored the effect of order-picking list sizes in determining the number of requested items or visited locations. To conduct a detailed analysis, the experiment investigated ten different pick-list sizes that include three to a hundred items. In contrast, most previous studies only considered a maximum of five lists with a maximum of fifty items (Petersen, 2002; Petersen et al., 2004; Berglund and Batta, 2012).

The resulting experiment uses a $4 \times 5 \times 7 \times 10$ full factorial design. For each combination, 10,000 orders were randomly generated based on the given pick-list size to estimate the average tour length within a $1 \%$ relative error with probability of $95 \%$. We are confident that 10,000 orders were enough after conducting an experiment on a sample problem in which the warehouse had $\mathrm{M}$ size with 2:1 ratio, randomized storage was applied and a pick-list of 15 , with a sample mean of 2220.4 and a standard deviation of 167.5. Additionally, two replications were performed by changing the seed in a random number generator. The performance measure was the average tour length for the picker to visit all requested locations described in 10,000 randomly-generated orders, yielding a total of 2,800 observations. These observations were analyzed by full factorial mixed-model ANOVA using IBM Minitab commercial statistics software version 16.2.4 for Microsoft Windows 8.

\section{RESULTS}

Table 3 shows the results of the full factorial experiment analysis (the ANOVA table) on average tour length. The results show that there is sufficient evidence of a difference between the levels of each main factor and their all-way combinations in terms of average tour length because their p-values were less than 0.01 (enabling the null hypothesis to be rejected). Table 3 also shows that the picklist size and number of picking aisles explain the largest portion of the variation in average tour length based on their high sequential sum of square (Seq. SS) values. This result is expected because average tour length is expected to increase as the number of requested picks and warehouse size increase. It is also interesting to see that shape ratio had the least effect on average tour length of the main factors. Further detailed analysis was conducted to investigate the interaction effects. 
Table 3 ANOVA results for average tour length

\begin{tabular}{|c|c|c|c|c|c|}
\hline Source & df & Seq. SS & Adj. MS & $\mathbf{F}$ & $p$ \\
\hline Shape Ratio & 3 & $33,438,880$ & $11,146,293$ & 960.67 & $0.000^{*}$ \\
\hline Storage Policy & 6 & $223,152,600$ & $37,192,100$ & 3205.49 & $0.000^{*}$ \\
\hline No. Picking Aisles & 4 & $1,559,637,705$ & $389,909,426$ & 33605.24 & $0.000 *$ \\
\hline Pick-list Size & 9 & $2,086,053,452$ & $231,783,717$ & 19976.81 & $0.000^{*}$ \\
\hline Shape Ratio*Storage Policy & 18 & $6,314,550$ & 350,808 & 30.24 & $0.000^{*}$ \\
\hline Shape Ratio*No. Picking Aisles & 12 & $8,194,937$ & 682,911 & 58.86 & $0.000^{*}$ \\
\hline Shape Ratio*Pick-list Size & 27 & $25,907,568$ & 959,540 & 82.7 & $0.000^{*}$ \\
\hline Storage Policy*No. Picking Aisles & 24 & $40,191,658$ & $1,674,652$ & 144.33 & $0.000^{*}$ \\
\hline Storage PolicyPick-list Size & 54 & $29,018,748$ & 537,384 & 46.32 & $0.000^{*}$ \\
\hline No. Picking Aisles *Pick-list Size & 36 & $339,264,202$ & $9,424,006$ & 812.23 & $0.000^{*}$ \\
\hline Shape Ratio*Storage Policy*No. Picking Aisles & 72 & $2,424,239$ & 33,670 & 2.9 & $0.000^{*}$ \\
\hline Shape Ratio*Storage Policy*Pick-list Size & 162 & $3,750,137$ & 23,149 & 2 & $0.000^{*}$ \\
\hline Shape Ratio*No. Picking Aisles*Pick-list Size & 108 & $2,987,903$ & 27,666 & 2.38 & $0.000^{*}$ \\
\hline Storage Policy*No. Picking Aisles*Pick-list Size & 216 & $19,790,928$ & 91,625 & 7.9 & $0.000^{*}$ \\
\hline Shape Ratio*Storage Policy*No. Picking Aisles*Pick-list Size & 648 & $9,419,049$ & 14,536 & 1.25 & $0.000^{*}$ \\
\hline Error & 1400 & $16,243,693$ & 11,603 & & \\
\hline Total & 2799 & $4,405,790,250$ & & & \\
\hline
\end{tabular}

\subsection{Interactions with Warehouse Shape Ratio}

To analyze the statistical significance of the different levels of the interactions of the main factors, multiple comparisons were made using a series of $t$-tests with Bonferroni correction (Bonferrroni t-tests), based on a familywise error rate of $1 \%$. Table 4 summarizes the results of these multiple comparisons for shape ratio by pick-list sizes at each level, sorted in descending order on average tour length. Additionally, if there was no statistically significant difference between them then shape ratios are grouped and shown symbolically in the table according to the Bonferroni t-test results.

As seen in Table 4, there was no statistically significant difference in the effect on tour length between the $1: 1$ and 2:1 shape ratios for less than 40 picks. Additionally, it was also hard to differentiate statistically between these two ratios for most pick-list sizes greater than 20 picks. As the number of picks increases, however, 3:1 became significantly distinct from other shape ratios for offering the worst average tour length. To present a clearer comparison, shape ratios were compared with the baseline shape ratio of $2: 1$ in terms of the percentage difference in average tour length (see Figure 4). As seen in Figure 4, while 3:1 does not provide any savings over 2:1 for any pick-list sizes, 1:1 and $1: 2$ ratios reduce tour length for more than 30 picks by over $5 \%$ on average compared to $2: 1$. This shows that an elongated warehouse becomes increasingly inefficient as the number of picks increases. While this result is consistent with Petersen (1997), it contradicts Hall (1993) and Thomas and Meller (2014). There are several reasons of this conflict, so further discussion was provided below to resolve this.

First, while Petersen (1997), Hall (1993) and Thomas and Meller (2014) only presented results for Layout A, this study considers Layout B. Second, while Petersen (1997) and this study used an optimal routing algorithm, Hall (1993) and Thomas and Meller (2014) used routing heuristics to calculate order-picking tour length. It has been shown that there is a difference between optimal and routing heuristics algorithms of between $9 \%$ to $40 \%$ in Layout A (Petersen, 1997) and around 13\% in Layout B (Berglund and Batta, 2012) depending on the chosen heuristic. Hence, the chosen routing algorithm might have a strong impact on the results. Third, Petersen (1997) and this study assumed a fixed storage capacity in terms of the total number of storage locations whereas Hall (1993), and Thomas and Meller (2014) assumed a fixed storage area. This also causes a disruptive result because of the fact that "a wider warehouse results in fewer storage locations in a fixed area (Petersen, 1997)" due to increasing length of front and rear cross aisles. Moreover, Thomas and Meller (2014) were also different in considering multiple $P \& D$ points on the front side of the warehouse that are equally likely to be visited to deposit items at the end of a tour.

In order to resolve the abovementioned contradiction and provide a solid insight to the efficiency of deeper warehouses for high number of picks, an additional analysis regarding warehouse shape ratios is provided in the Appendix. In this analysis, an order picker is assumed to visit all of the available storage locations in a single tour. The results of this analysis also showed that the total tour length of an order picker is the minimum when width-to-depth ratios of a warehouse is less than 1.0. Please see Appendix for the details.

Further analysis was also conducted to gain more insights on shape ratio effects for varying warehouse sizes. The Bonferroni t-test was used to examine the statistical significance of the different levels of warehouse shape ratio for each level of warehouse size (see Table 5). Shape ratios were significantly different from each other for small warehouses but lost their significant effect on average tour length as warehouse size became extra-large (XL). This can be clearly seen by comparing the performance of the shape ratios with the base. As seen in Figure 5, while savings on average tour length from shape ratios $1: 1$ and 1:2 diminish, 
the disadvantage of 3:1 disappears as warehouse size increases. Even though this research differs in many ways, Thomas and Meller (2014) also reported a similar result that "larger warehouses are more elongated than smaller warehouses". For reasons stated above, if order pickers may have to traverse all picking aisles in a small warehouse then deeper warehouses reduce average tour length. However, as warehouse size increases, the requested locations become more dispersed so deep picking aisles may increase travel length. To facilitate travel between locations and reduce tour length, elongated warehouses seem to be favorable as warehouse capacity increases. Moreover, the same result also provides an important insight to warehouse managers: that deeper small storage order-picking zones reduce average tour length compared to wider zones.

Table 6 presents the results of multiple comparison tests of shape ratio by levels of storage policy. Shape ratios $3: 1$ and $2: 1$ are not significantly different for all storage policies except for A80. Additionally, 1:2, 1:1 and 2:1 shape ratios are not statistically different from each other based on the application of a storage policy. Hence, it can be concluded that changes in storage or demand policies do not significantly affect the choice of shape ratio between 3:1 and 2:1 or between 1:2, 1:1 and 2:1. To clarify this, Figure 6 compares shape ratio with the base for varying storage policies. It clearly indicates that deeper warehouses, such as $1: 1$ and $1: 2$, provide greater savings on average tour length than wider warehouses (2:1 and 3:1) when across-aisle storage is implemented regardless of demand policy. Finally, $1: 1$ provides approximately $4 \%$ more savings on average tour length than $2: 1$ in within-aisle, diagonal or randomized storage policies.

This analysis showed that the 1:2 shape ratio outperforms other ratios for small-size storage areas with a high number of picks while 1:1 is superior and robust at most pick-list and warehouse sizes, regardless of storage and demand policies. Therefore, in contrast to several previous studies, this study reveals that 1:1 shape ratio may be preferred for small and medium-sized order-picking warehouses that utilize a central cross aisle to facilitate travel between moderate numbers of locations when all material flows go through a central P\&D point.

$\underline{\text { Table } 4 \text { Multiple comparison test for warehouse shape ratio by pick-list size on average route length }}$

\begin{tabular}{|c|c|c|c|c|c|c|c|c|c|}
\hline \multicolumn{10}{|c|}{ Pick-list Size } \\
\hline SR & $\begin{array}{r}3 \\
\text { Mean }\end{array}$ & SR & $\begin{array}{r}5 \\
\text { Mean }\end{array}$ & SR & $\begin{array}{c}10 \\
\text { Mean }\end{array}$ & SR & $\begin{array}{c}15 \\
\text { Mean }\end{array}$ & SR & $\begin{array}{l}20 \\
\text { Mean }\end{array}$ \\
\hline 1:2 & 922.9 & $3: 1$ & 1187.2 & $3: 1$ & 1655.4 & $3: 1$ & 2011.2 & $3: 1$ & 2259.4 \\
\hline $3: 1$ & 900.8 & $1: 2$ & 1185.6 & $1: 2$ & 1602.2 & $1: 2$ & 1907.3 & $2: 1$ & 2144.5 \\
\hline $2: 1$ & 837.5 & $2: 1$ & 1102.9 & $2: 1$ & 1552.8 & $2: 1$ & 1885.5 & $1: 2$ & 2109.5 \\
\hline $1: 1$ & 837.0 & $1: 1$ & 1074.2 & $1: 1$ & 1509.2 & $1: 1$ & 1834.0 & $1: 1$ & 2066.7 \\
\hline \multicolumn{3}{|c|}{30} & 40 & \multicolumn{3}{|c|}{50} & 75 & \multicolumn{2}{|r|}{100} \\
\hline $3: 1$ & 2666.4 & $3: 1$ & 2978.2 & $3: 1$ & 3213.6 & $3: 1$ & 3665.0 & $3: 1$ & 3966.7 \\
\hline $2: 1$ & 2526.3 & $2: 1$ & 2807.0 & $2: 1$ & 3005.2 & $2: 1$ & 3443.1 & $2: 1$ & 3685.0 \\
\hline $1: 1$ & 2443.5 & $1: 1$ & 2661.2 & $1: 1$ & 2870.4 & $1: 1$ & 3213.6 & $1: 1$ & 3374.3 \\
\hline $1: 2$ & 2431.7 & $1: 2$ & 2624.6 & $1: 2$ & 2762.2 & $1: 2$ & 3034.4 & $1: 2$ & 3219.8 \\
\hline
\end{tabular}

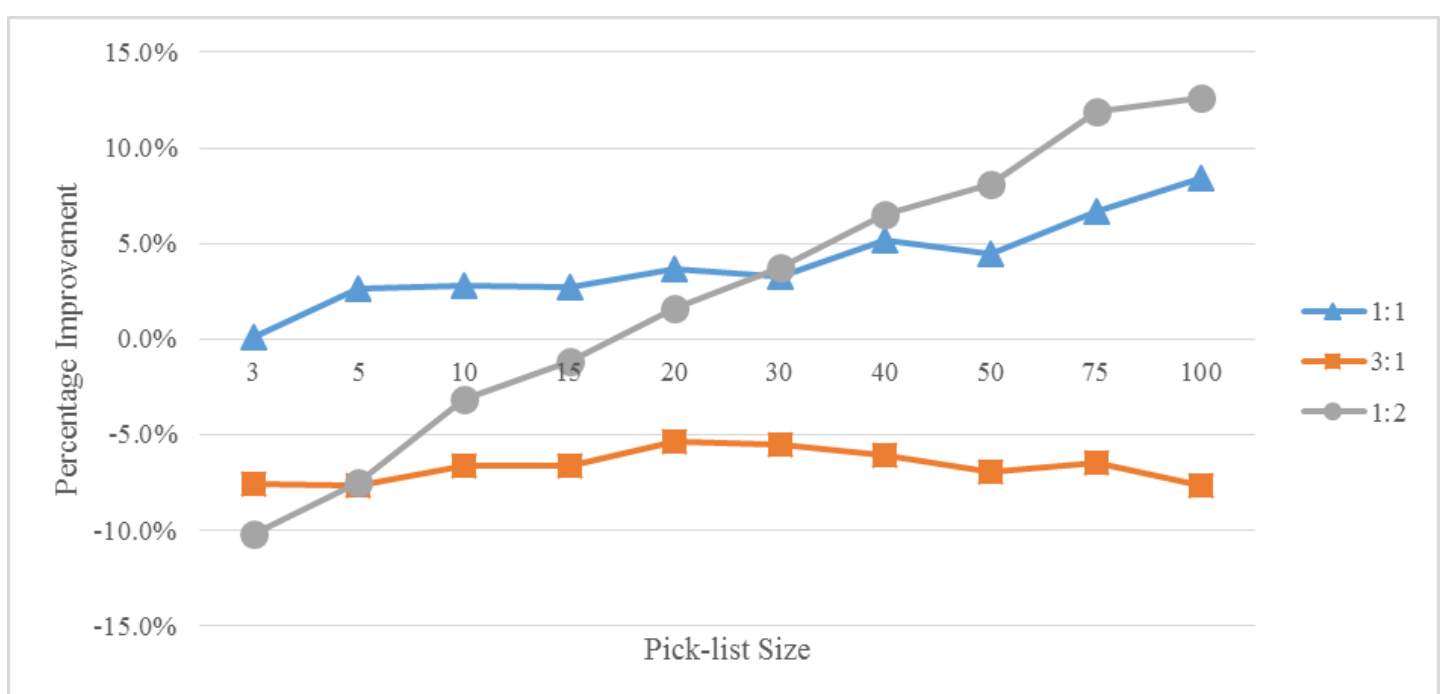

Figure 4 Percent savings on average tour length that the level of shape ratios provided over the base shape ratio 2:1 as pick-list sizes change 
Table 5 Multiple comparison test for warehouse shape ratio by warehouse size on average route length

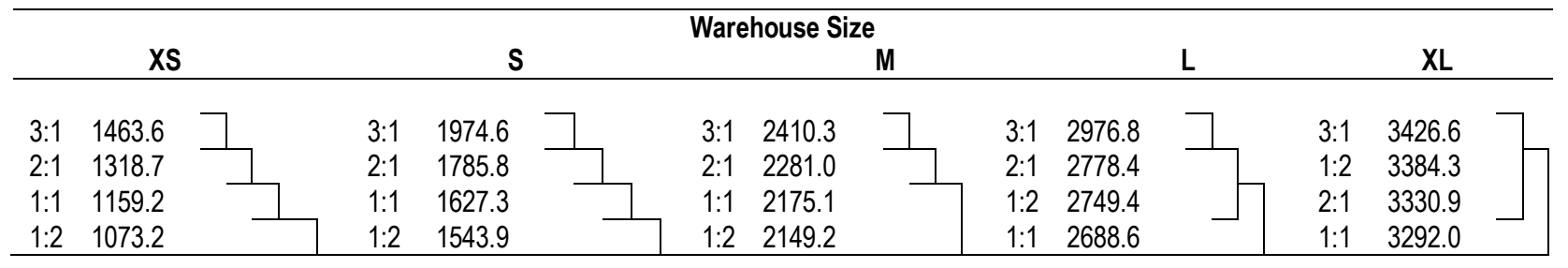

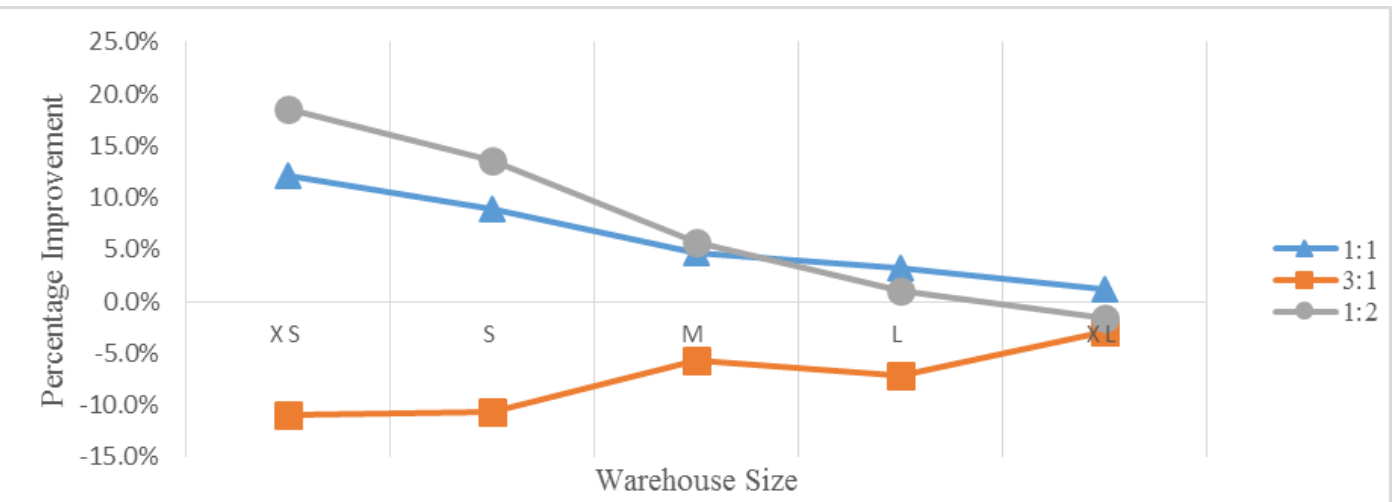

Figure 5 Percent savings on average tour length that the level of shape ratios provide over the base shape ratio 2:1 as warehouse sizes change

Table 6 Multiple comparison test for warehouse shape ratio by storage policy on average route length

\begin{tabular}{|c|c|c|c|c|c|c|c|}
\hline \multicolumn{8}{|c|}{ Shape Ratio } \\
\hline \multicolumn{2}{|r|}{ RND } & \multicolumn{2}{|r|}{ A50 } & \multicolumn{2}{|r|}{ D50 } & \multicolumn{2}{|r|}{ W50 } \\
\hline $3: 1$ & 2894.2 & $3: 1$ & 2711.8 & $3: 1$ & 2590.8 & $3: 1$ & 2579.2 \\
\hline $2: 1$ & 2690.4 & $2: 1$ & 2533.6 & $2: 1$ & 2450.4 & $2: 1$ & 2429.3 \\
\hline $1: 1$ & 2573.9 & $1: 1$ & 2364.4 & $1: 2$ & 2367.0 & $1: 1$ & 2324.1 \\
\hline 1:2 & 2569.2 & $1: 2$ & 2354.5 & $1: 1$ & 2362.9 & $1: 2$ & 2323.7 \\
\hline & A80 & & D80 & & W80 & & \\
\hline $3: 1$ & 2382.7 & $3: 1$ & 1999.4 & $3: 1$ & 1994.6 & & \\
\hline $2: 1$ & 2179.5 & $2: 1$ & 1942.3 & $2: 1$ & 1867.4 & & \\
\hline $1: 1$ & 1984.0 & $1: 2$ & 1900.4 & $1: 2$ & 1846.0 & & \\
\hline $1: 2$ & 1899.4 & $1: 1$ & 1891.7 & $1: 1$ & 1818.1 & & \\
\hline
\end{tabular}

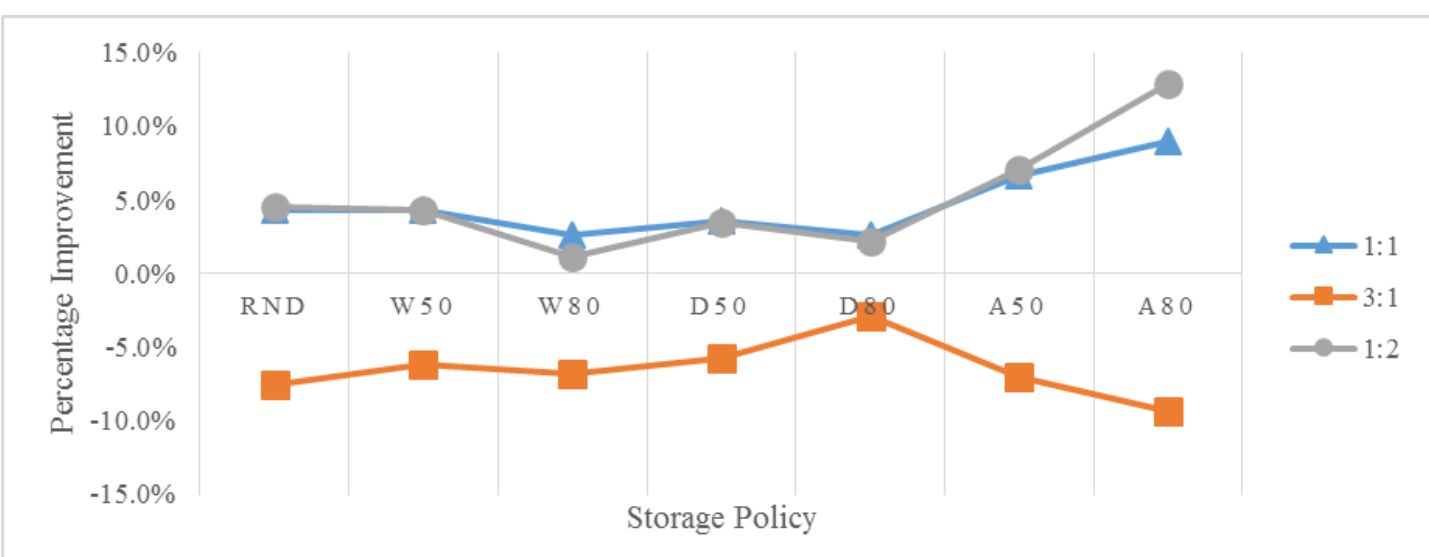

Figure 6 Percent savings on average tour length that the levels of shape ratio provide over the base shape ratio 2:1 when different storage policies are applied 


\subsection{Effects of Interactions with Storage Policy}

To determine the significance of levels of storage policy for efficient warehouse management, Bonferroni ttests were applied at each level of pick-list and warehouse sizes. Table 7 presents the results of the multiple comparisons of pick-list sizes and storage policies. The randomized storage policy was significantly different from others in most cases. However, there was also no statistically significant difference between randomized and class-based storage policies in a low-level demand policy for a very high number of picks; i.e. 100 picks. The reason of this result is that these policies require order pickers to traverse almost all picking aisles due to the high number of picks distributed throughout the warehouse. Another interesting result is the general lack of a significant difference across variations of class-based storage policy for low-level demand policy. However, the implementations of class-based storage policies with high-level demand are significantly different for low and moderate numbers of picks $(<50)$ even though they become similar at a high number of picks. In most picklist sizes, there is no statistically significant difference between diagonal and within-aisle storage policies, irrespective of demand policy. Figure 7 also shows that levels of class based storage policies are superior to randomized storage based on the percentage savings on average tour length. As seen in both Table 7 and Figure 7, within-aisle storage is generally the best policy, although diagonal is the best when only 3 locations are visited. Finally, Figure 7 also shows that the improvement in tour length increases as the demand activities of class-A SKUs increase. Interestingly, some of these results also contradict previous results.

From their investigation of the best location for a central cross aisle, Berglund and Batta (2012) concluded that there is a slight difference between within-aisle and acrossaisle storage policies in general. However, they highlighted that across-aisle storage is superior to within-aisle storage for low and moderate numbers of picks whereas within-aisle is better for a high number of picks. They also reported that diagonal storage is outperformed by both across-aisle and within-aisle storage policies. Hsieh and Tsai (2006) reported another interesting result: that implemented class-based storage policies have no statistically significant effects on order-picking tour length. As previously discussed, both Berglund and Batta (2012) and Hsieh and Tsai (2006) used heuristics to calculate order-picking tour lengths. In contrast to these studies, several previous studies provided results that are consistent with this study. Le-Duc and De Koster (2005), for example, found that a within-aisle storage policy is close to optimal in a variant of the two-block warehouse layout while Petersen $(1999 ; 2002)$ showed that within-aisle is better than across-aisle and across-aisle is better than randomized storage in Layout $\mathrm{A}$. These studies even concluded that the gap between these storage policies reduces as the number of picks increases.

Last analysis was performed to compare each level of storage policies with respect to changes in warehouse size. The results of multiple comparisons of storage policies showed that changes on warehouse size do not change the effect of storage policies. Therefore, only brief results of this analysis is presented for the sake of the flow. These results showed that randomized storage is significantly different from and outperformed by other storage policies. W80 and D80 appear to be similar and superior policies for any warehouse size. Additionally, the results indicated that classbased storage policies at a low-level demand policy are not significantly different for any warehouse size. Additionally, across-aisle storage policy with a high-level demand policy (A80) appears to be better than D50 but worse than D80.

Table 7 Multiple comparison test for storage policy by pick-list size on average route length

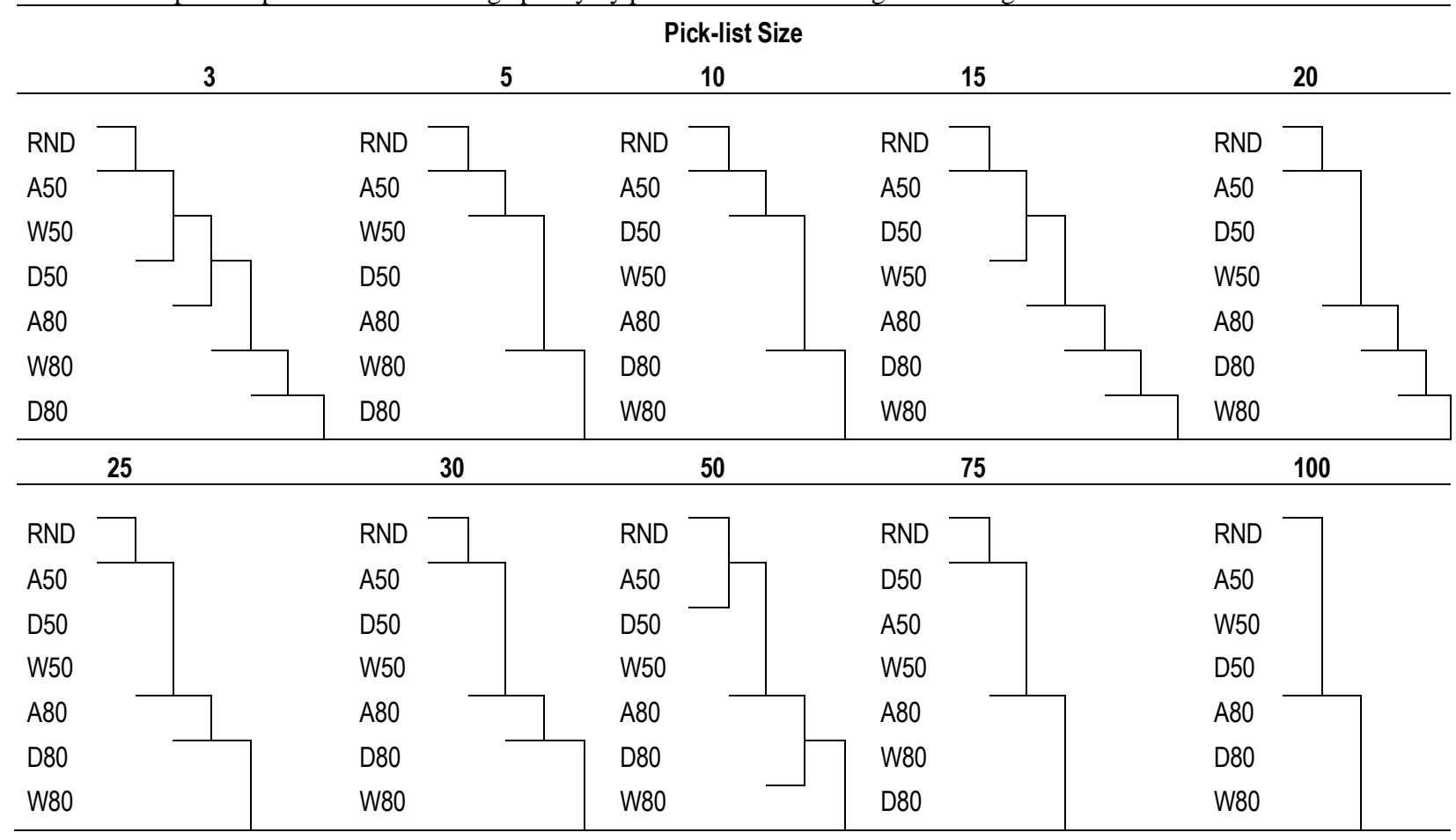




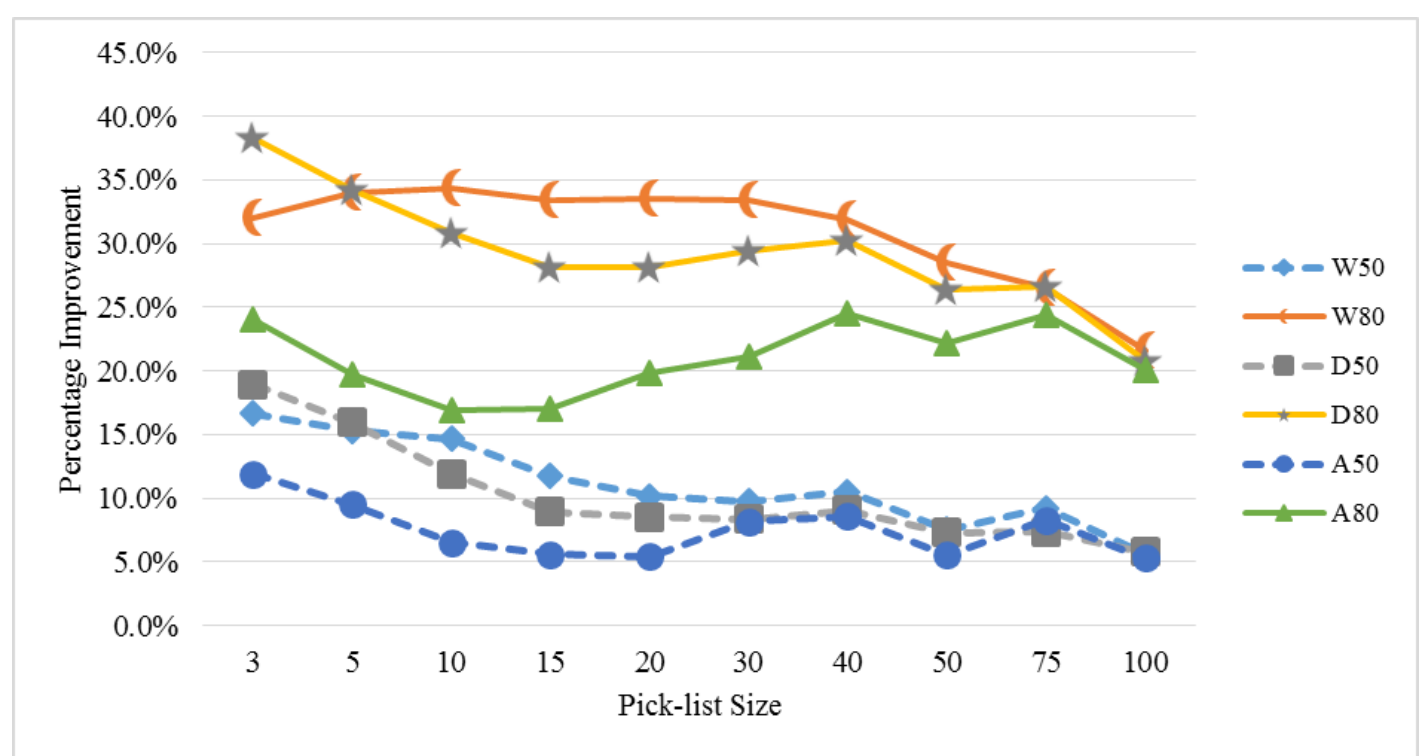

Figure 7 Percent savings on average tour length that the levels of class-based storage policies provide over randomized storage for varying number of picks

It can be concluded that within-aisle storage should be strongly recommended for practitioners in both one-block and two-block warehouses because of its ease of application and efficient tour length. While within-aisle storage provides a $30 \%$ reduction in tour length over randomized storage when class-A SKUs are very active, the saving falls to $7.5 \%$ on average as their activity level decreases. Even though a diagonal storage policy offers similar savings with withinaisle storage and even it has more savings for 3 picks, it cannot be recommended to practitioners because it is difficult to implement.

\section{CONCLUDING REMARKS}

This study is the first to evaluate the effects of both operational and design parameters on order-picking tour length in two-block traditional warehouse layouts. No prior research has completely investigated the impact on optimal route length of various warehouse shapes, sizes, pick-list length, storage policies and demand policies, and their interactions. Because the few studies that investigated the effects of specific parameters on order-picking route length used different heuristics, they have provided conflicting results. This study has also provided a detailed discussion about those conflicts. For instance, while several studies recommend wider warehouses when the number of picks increases, our results indicate that warehouses get deeper as the number of stops increases. Hence, a 1:1 shape ratio can be recommended to warehouse managers because it provides low tour lengths for any number of picks between 3 and 100 . However, this study also showed that deeper warehouse configurations, such as $1: 1$ and 1:2, are less able to reduce tour length over the base design $2: 1$ as warehouse size increases. For instance, while 1:1 and 1:2 ratio, small-sized warehouses provide $12 \%$ to $18 \%$ savings on average tour length, respectively, in comparison with $2: 1$, similarly configured, large-sized warehouses do not reduce tour length. Because large warehouses cause long travel distances, warehouse managers usually prefer to create smaller order-picking zones to reduce travel distance. Our results suggest deeper zones (1:1) for large warehouses in the light of previous discussions. Additionally, deeper warehouses outperform wider warehouses for any storage and demand policies, but especially for across-aisle storage. Thus, a shape ratio of 1:1 is a robust design for small- and medium-sized storage areas.

Many previous studies have shown that class-based storage policies require significantly less tour length than randomized storage in order-picking warehouses, although randomized storage increases storage utilization. Whereas the impact of randomized and variants of class-based storage policies on tour length has been extensively studied for oneblock warehouses, there are insufficient studies for twoblock warehouses and contradictory results for warehouse layouts. This study therefore aimed to resolve these conflicts and provide solid insights about the application of storage policies for warehouse managers. Specifically, our experiment investigated whether within-aisle storage policy is still significantly better than across-aisle storage policy in two-block warehouses. The results showed that within-aisle storage is robust with respect to varying warehouse sizes. However, it has a decreasing effect on tour length as the number of required picks increases because this causes order pickers to traverse all aisles.

This study has several practical limitations, particularly congestion and multiple P\&D points. First, it assumed that order-picking tour length is the main performance measure. However, although order-picking time is proportional to tour length, increasing aisle congestion may affect the implementation of storage policies. Additionally, warehouse sizes and shape ratios may also affect congestion. Second, regarding the number of $\mathrm{P} \& \mathrm{D}$ points, it assumed that orderpickers begin and end their travel at a single $\mathrm{P} \& \mathrm{D}$ point. In practice, however, this assumption would only be appropriate if pickers must take their order lists from a central process station or if all picked items must be wrapped at a central shrink-wrap machine. Additionally, warehouse managers may worry about implementing optimal tours because their complexity may confuse pickers. However, emerging technologies and their use in warehouses can easily relieve their concerns regarding optimal routes. For instance, augmented reality devices, such as Google glasses, GPS- 
mounted forklifts or autonomous vehicles, have little difficulty finding their way through a warehouse. In short, this study provided valuable results for warehouse managers regarding optimal route analysis. Like previous studies, it also showed that warehouse managers can easily improve their order-picking operations by using optimal routes.

\section{ACKNOWLEDGEMENTS}

This research was conducted under a project supported by the TUBITAK (The Scientific and Technological Research Council of Turkey) under Grant 214M220.

\section{REFERENCES}

Bartholdi, J.J., and Hackman, S.T. (2008), Warehouse \& Distribution Science: Release 0.89, Supply Chain and Logistics Institute, Georgia Tech, Atlanta, US.

Bassan, Y., Roll, Y., and Rosenblatt, M.J. (1980). Internal layout design of a warehouse. AIIE Transactions, 12(4), pp. 317322.

Berglund, P., and Batta, R. (2012). Optimal placement of warehouse cross-aisles in a picker-to-part warehouse with class-based storage. IIE Transactions, 44(2), pp. 107-120.

Francis, R.L. (1967). On some problems of rectangular warehouse design and layout. Journal of Industrial Engineering, 18(10), pp. 595-604.

Futch, M. (2017). Rise of the warehouse robots. Material Handling \& Logistics, http://www.mhlnews.com/technologyautomation/rise-warehouse-robots, accessed 2017-10-29.

Hall, R.W. (1993). Distance approximations for routing manual pickers in a warehouse. IIE Transactions, 25(4), pp. 76-87.

Hsieh, L.F., and Tsai, L. (2006). The optimum design of a warehouse system on order picking efficiency. The International Journal of Advanced Manufacturing Technology. 28(5), pp. 626-637.

Ho, Y.C., Su, T.S., and Shi, Z.B. (2008). Order-batching methods for an order-picking warehouse with two cross aisles. Computers \& Industrial Engineering, 55(2), pp. 321-347.

Jarvis, J.M., and McDowell, E.D. (1991). Optimal product layout in an order picking warehouse. IIE Transactions, 23(1), pp. 93-102.

Le-Duc, T., and De Koster, R.M.B. (2005). Travel distance estimation and storage zone optimization in a 2-block classbased storage strategy warehouse. International Journal of Production Research, 43(17), pp. 3561-3581.

Manrodt, K. (2018). The top distribution center metrics for 2016. Supply Chain Digest., http://www.scdigest.com/ontarget/1605-31-1.php?cid $=107641 \% 22 \&$ ctype $=$ content $/, \quad$ accessed 2018-05-24.
Petersen, C.G., and Schmenner, R.W. (1999). An evaluation of routing and volume-based storage policies in an order picking operation. Decision Sciences, 30(2), pp. 481-501.

Petersen, C.G. (2000). An evaluation of order picking policies for mail order companies. Production and Operations Management, 9(4), pp. 319-335.

Petersen, C.G. (1999). The impact of routing and storage policies on warehouse efficiency. International Journal of Operations \& Production Management, 19(10), pp. 1053-1064.

Petersen, C.G. (1997). An evaluation of order picking routing policies. International Journal of Operations \& Production Management, 17(11), pp. 1098-1111.

Petersen, C.G. (2002). Considerations in order picking zone configuration. International Journal of Operations \& Production Management, 22(7), pp. 793-805.

Petersen, C.G., and Aase, G. (2004). A comparison of picking, storage, and routing policies in manual order picking. International Journal of Production Economics, 92(1), pp. 11-19.

Petersen, C.G., Aase, G.R., and Heiser, D.R. (2004). Improving order-picking performance through the implementation of class-based storage. International Journal of Physical Distribution \& Logistics Management, 34(7), pp. 534-544.

Park, B.C., and Lee, M.K. (2007). Closest open location rule under stochastic demand. International Journal of Production Research, 45(7), pp. 1695-1705.

Ratliff, H.D. and Rosenthal, A.S. (1983), "Order-picking in a rectangular warehouse: a solvable case of the traveling salesman problem", Operations Research, 31(3), pp.507-521.

Roodbergen, K.J., and Vis, I.F. (2006). A model for warehouse layout. IIE Transactions, 38(10), pp. 799-811.

Roodbergen, K.J., and De Koster, R. (2001). Routing order pickers in a warehouse with a middle aisle. European Journal of Operational Research, 133(1), pp.32-43.

Scholz, A., Henn, S., Stuhlmann, M., and Wäscher, G. (2016). A new mathematical programming formulation for the singlepicker routing problem. European Journal of Operational Research, 253(1), pp. 68-84.

Shead, S. (2017). Amazon now has 45,000 robots in its warehouses. Business Insider UK, http://uk.businessinsider.com/amazonsrobot-army-has-grown-by-50-2017-1, accessed 2017-10-28.

Thomas, L.M., and Meller, R.D. (2014). Analytical models for warehouse configuration. IIE Transactions, 46(9), pp. 928947.

Tompkins, J.A., White, J.A., Bozer, Y.A., and Tanchoco, J.M.A. (2010), Facilities planning, John Wiley \& Sons.

Vaughan, T.S., and Petersen, C.G. (1999). The effect of warehouse cross aisles on order picking efficiency. International Journal of Production Research, 37(4), pp. 881-897.

\section{APPENDIX: EXTREME CASE ANALYSIS FOR DETERMINING OPTIMAL SHAPE RATIO}

Suppose that all storage locations in the warehouse must be visited in a single tour in the extreme case. An order picker begins the tour at the $\mathrm{P} \& \mathrm{D}$ point and traverses all aisles using a serpentine path without necessitating a central cross aisle. Figure A.1 presents the optimal tour paths for example warehouses with even and odd number of picking aisles, respectively. Suppose that the total number of storage locations in a warehouse is fixed at $T$ in terms of PU. Let $L$ be the number of locations on the leftmost and rightmost racks, and $p$ be the width of the square storage location in a rack. Remember that $n, W, D, a$ and $b$ are number of picking aisles, warehouse width, warehouse depth, picking aisles' width and cross aisles' width, respectively. Thus, $T=2 \cdot n \cdot L=2 \cdot n \cdot(D-2 b)$ and $W=n \cdot(a+2 p)$. If travel starts and ends at the central P\&D point, total route lengths (Tour) to visit all locations through traversing all aisles for even and odd number of picking aisles are

- If $n$ is even, $R_{e}=n \cdot(L+b)+2(n-1)(a+2 p)$, and

- If $n$ is odd, $R_{o}=(n-1) \cdot(L+b)+2\left(L+\frac{b}{2}\right)+2(n-1)(a+2 p)$.

While the last terms in these equations indicate across-aisle travel through the horizontal cross aisles, the other terms indicate within-aisle travels through the vertical picking aisles. The reason of the difference between the equations is that the picker has to return from the last aisle after traversing it when there are odd number of picking aisles. 


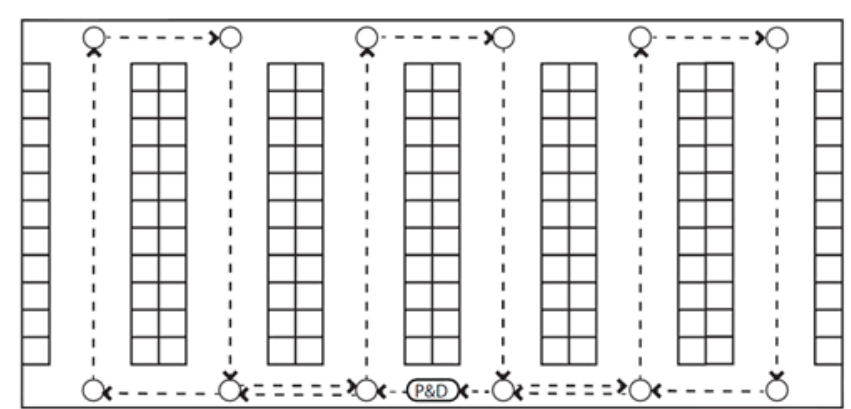

a) six aisles

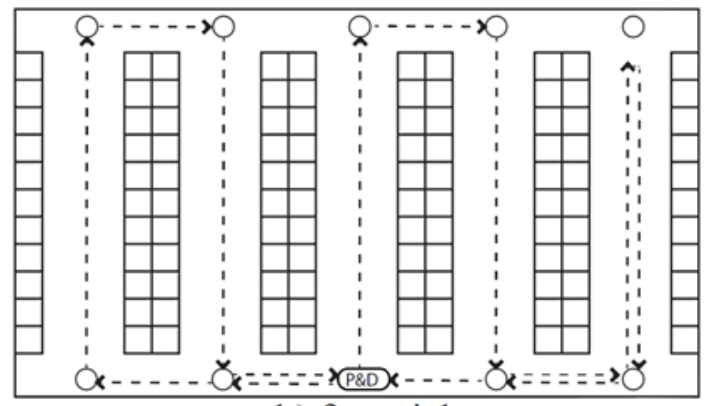

b) five aisles

Figure A.1 Optimal routes for the extreme case in warehouses with even and odd number of picking aisles

Let indicate width to depth ratio, $r=W / D$. Replacing $D$ and $W$ with the functions above, the following equations are obtained.

$$
\begin{aligned}
& 2(a+2 p) n^{2}+2 n r-T r=0 \\
& L^{2}-2 b L-\frac{T A}{2 r}=0
\end{aligned}
$$

The positive roots of these equations are as the followings.

$$
\begin{aligned}
& n=\frac{-r \sqrt{r^{2}+2(a+2 p) T}}{2(a+2 p)} \\
& L=\frac{2 b r+\sqrt{4 b^{2} r^{2}+2(a+2 p) r T}}{2 r}
\end{aligned}
$$

After inserting $n$ and $L$ in $R_{e}$ and $R_{o}$,

$$
\begin{aligned}
& R_{e}=-2 a+4 p+\left(\frac{\left(4(a+b+2 p) r+\sqrt{2} \sqrt{r\left(2 b^{2} r+(a+2 p) T\right.}\right)(-r+\sqrt{r(r+2(a+2 p) T)})}{4(a+2 p) r}\right) \\
& R_{o}=-2 a+b-4 p-r+\sqrt{r(r+2(a+2 p) T)}+\frac{2 b r+\sqrt{4 b^{2} r^{2}+2(a+2 p) r T}}{r}+\left(2 b+\frac{\sqrt{r\left(2 b^{2} r+(a+2 p) T\right)}}{\sqrt{2} r}\right)(-1+ \\
& \left.\frac{-r+\sqrt{r(r+2(a+2 p) T}}{2(a+2 p)}\right)
\end{aligned}
$$

In order to find the optimal shape ratio in both cases, the first and second order conditions of $R_{e}$ and $R_{o}$ analyzed. Given that $\frac{d R_{e}}{d r}$ is the function of the first derivative of $R_{e}$ with respect to $r$, it is seen that, $\frac{d R_{e}}{d r}$ is always greater than 0 that indicates an increasing function of $R_{e}$ with increasing $r$. Thus, there is no local optimal $r$ that makes $\frac{d R_{e}}{d r}=0$. Hence, because of the extreme value theorem the lowest possible value of $r$ minimizes $R_{e}$. Because $R_{e}$ is valid for even number of aisles, $n$ should be 2 and resulting optimal shape ratio $r_{e}^{*}=8 \cdot(a+2 p) /(T+8 b)$ which also makes second derivative of $R_{e}>0$. For the numerical solutions, we consider very-narrow, narrow and wide-aisle configurations where $a=b$ and equal to 1,2 and 3 PU, respectively. $p$ is 1 PU. Figure A.2 demonstrates optimal shape ratios for the case of even number of aisles. As seen in the figure, the shape ratio is always less than 1 and it decreases as the capacity increases. Hence, this result presents that deeper warehouses reduce total tour length in the extreme case.

For the case of odd number of aisles, suppose that $R_{e}^{\prime}=\frac{d R_{e}}{d r}$ and $R_{e}^{\prime \prime}=\frac{d^{2} R_{e}}{d r^{2}}$. When $R_{e}^{\prime}=0$ is numerically solved, it is seen that there are single roots (critical points) for the set of given values of $a, b$ and $T$ and $p$ above. Because $R_{e}^{\prime \prime}>0$ at these critical points $\left(r_{o}^{*}\right)$, these are global minimums. Thus, Figure A.3 demonstrates the optimal shape ratios for odd number of picking aisles. As seen in the figure, the optimal warehouse layout is almost three times deeper than its width to reduce order picking tour length in the extreme case. 


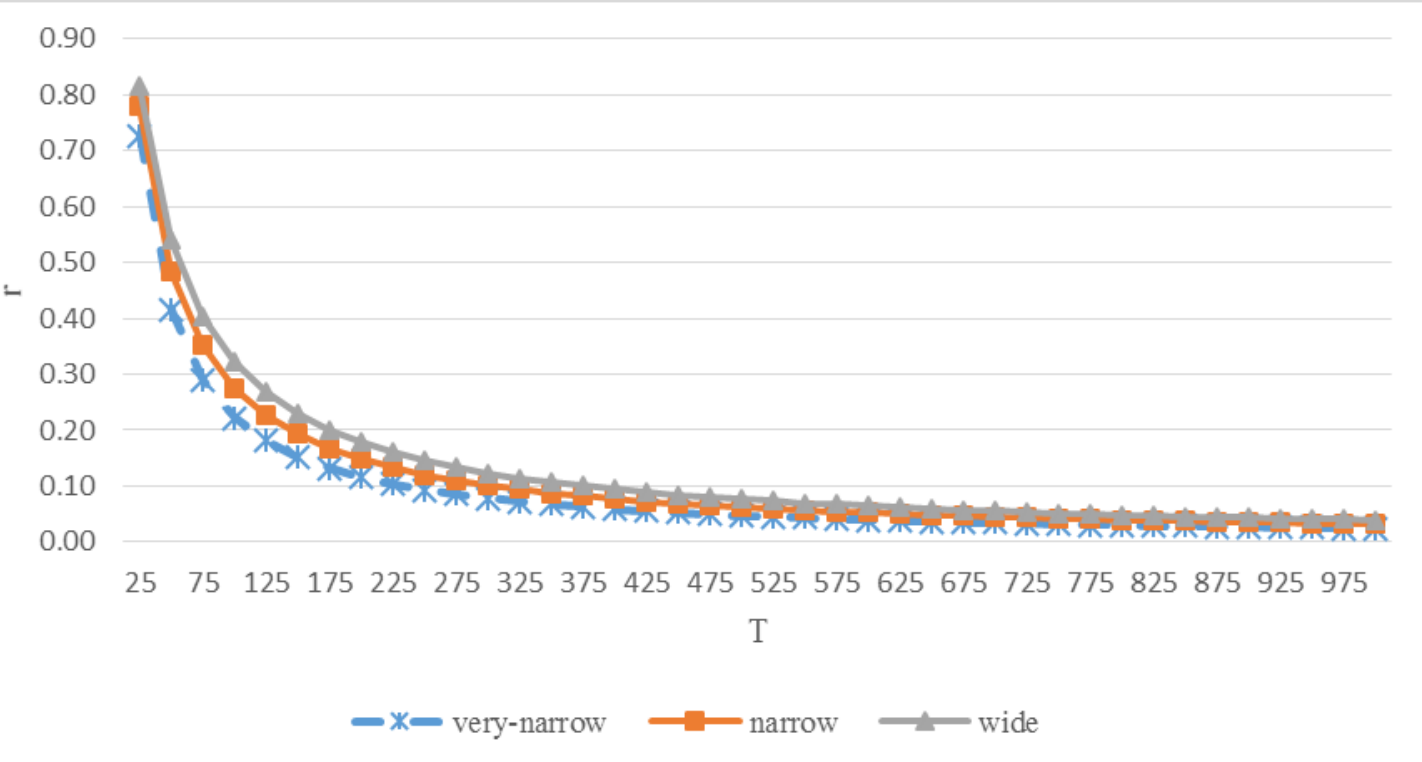

Figure A.2 Optimal shape ratios for given aisle widths and warehouse capacities when there are two picking aisles

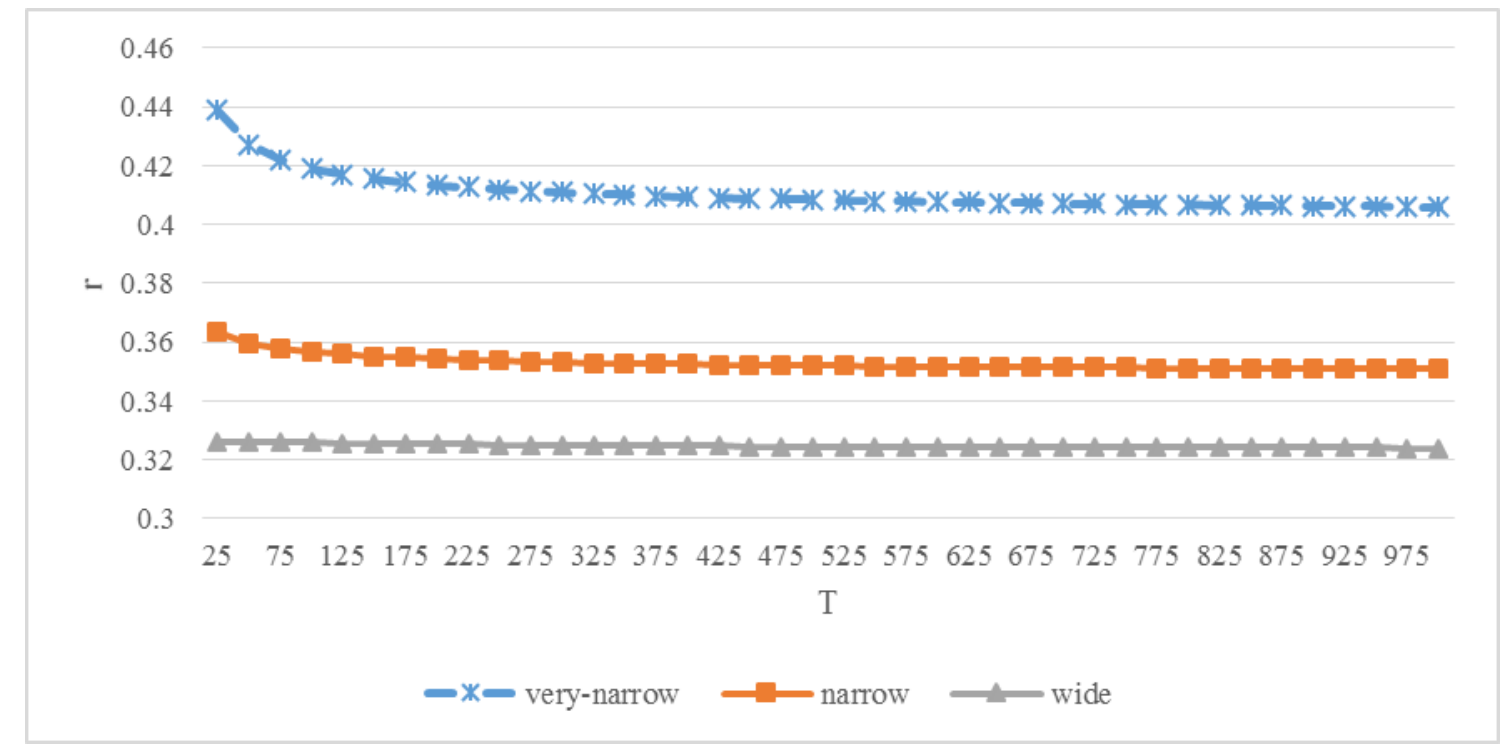

Figure A.3 Optimal shape ratios when there are odd number of aisles

$\frac{d R_{e}}{d r}=\frac{1}{4(a+2 p) r^{2}}\left(r\left(4(a+b+2 p) r+\sqrt{2} \sqrt{r\left(2 b^{2} r+(a+2 p) T\right)}\right)\left(-1+\frac{r+(a+2 p) T}{\sqrt{r(r+2(a+2 p) T)}}\right)-(4(a+b+2 p) r+\right.$ $\left.\sqrt{2} \sqrt{r\left(2 b^{2} r+(a+2 p) T\right)}\right)(-r+\sqrt{r(r+2(a+2 p) T)})+r\left(4(a+b+2 p)+\frac{4 b^{2} r+(a+2 p) T}{\sqrt{2} \sqrt{r\left(2 b^{2} r+(a+2 p) T\right)}}\right)(-r+$ $\sqrt{r(r+2(a+2 p) T)}))$

$\frac{d R_{o}}{d r}=-1+\frac{r+(a+2 p) T}{\sqrt{r(r+2(a+2 p) T)}}+\frac{2 b+\frac{4 b^{2} r+(a+2 p) T}{\sqrt{2} \sqrt{r\left(2 b^{2} r+(a+2 p) T\right)}}}{r}+\frac{\left(2 b+\frac{\sqrt{r\left(2 b^{2} r+(a+2 p) T\right)}}{\sqrt{2} r}\right)\left(-1+\frac{r+(a+2 p) T}{\sqrt{r(r+2(a+2 p) T)}}\right)}{2(a+2 p)}+\frac{T(2 a+4 p+r-\sqrt{r(r+2(a+2 p) T)})}{4 \sqrt{2} r \sqrt{r\left(2 b^{2} r+(a+2 p) T\right)}}-$ $\frac{2 b r+\sqrt{4 b^{2} r^{2}+2(a+2 p) r T}}{r^{2}}$ $\frac{d^{2} R_{o}}{d r^{2}}=\left((a+2 p) T\left(-\sqrt{2}\left(1-4 b^{2}\right)^{2} r^{3} T+12 \sqrt{2}(a+2 p)^{2} T^{2} \sqrt{r(r+2(a+2 p) T)}+2(a+\right.\right.$ $2 p) r T\left(-8 a T \sqrt{r\left(2 b^{2} r+(a+2 p) T\right)}-8 b T \sqrt{r\left(2 b^{2} r+(a+2 p) T\right)}-16 p T \sqrt{r\left(2 b^{2} r+(a+2 p) T\right)}\right.$ $\left.+16 \sqrt{2} b^{2} \sqrt{r(r+2(a+2 p) T)}+\sqrt{2}(3+T) \sqrt{r(r+2(a+2 p) T)}\right)+r^{2}\left(-32 a b^{2} T \sqrt{r\left(2 b^{2} r+(a+2 p) T\right)}\right.$ $-32 b^{3} T \sqrt{r\left(2 b^{2} r+(a+2 p) T\right)}+\sqrt{2} T \sqrt{r(r+2(a+2 p) T)}+16 b^{2}\left(-4 p T \sqrt{r\left(2 b^{2} r+(a+2 p) T\right)}\right.$ $+\sqrt{2} \sqrt{r(r+2(a+2 p) T)})))) /\left(16\left(r\left(2 b^{2} r+(a+2 p) T\right)\right)^{3 / 2}(r(r+2(a+2 p) T))^{3 / 2}\right)$

Ömer Öztürkoğlu is an Associate Professor in Business Administration at Yaşar University, Izmir, Turkey. After completing his undergraduate and master studies at the Department of Industrial Engineering in Dokuz Eylul and Erciyes Universities in Turkey, respectively. He then completed his master and doctoral studies in Industrial and Systems Engineering at Auburn 
University, Alabama, USA. He teaches related courses to Logistics Facilities, Warehousing, and Production and Operations Analysis. In general, his research interests are warehousing, production and operations systems analysis and design.

Deniz Hoşer received her B.Sc. and M.Sc. degrees in Industrial Engineering from Yaşar University in years 2015 and 2018 , respectively. During her master degree period, she worked as a research assistant in a project funded by the TUBITAK (The Scientific and Technological Research Council of Turkey). Her research interests include routing in logistics systems and designing warehousing and production systems. 